\title{
Scanning Electron Microscopic Study on the Head Lice Eggs Detected in Korean Children
}

*Correspondence to:
Chang BS,
Tel: +82-41-660-1584
Fax: +82-41-660-1590
E-mail: bschang@hanseo.ac.kr

Received May 31, 2014

Revised June 24, 2014

Accepted June 26, 2014

\author{
Mi Soon Park, Byung Soo Chang $^{1, *}$ \\ Departments of Health Care and ${ }^{1}$ Cosmetology, Hanseo University, Seosan 356-706, Korea
}

\begin{abstract}
Fine structural characteristics of eggs (nits) found on the scalp hairs of Korean children were observed with scanning electron microscopy. An egg is structurally composed of four parts: the cementum, nit body, operculum, and aerophyle. The total length of an egg is about $1.5 \mathrm{~mm}$. The glue secreted from the female louse completely surrounds the $1 \mathrm{~mm}$ hair shaft and forms the cementum. The thickness of the cementum at the end of the nit body was found to be more than 5 times the thickness at the end toward the scalp. The nit body is shaped like a goblet with a very smooth surface. The operculum and aerophyles are located at the apiculus area. In the circular operculum, there are 10 aerophyles concentrated on the side of the hair shaft surface that are shaped like a dome. Three aerophyles in the center are surrounded by 7 aerophyles. Each aerophyle is dome shaped with a diameter of $65 \mu \mathrm{m}$ and a respiratory pathway with a $15 \sim 25 \mu \mathrm{m}$ opening at the center. On the cut surface where the operculum is separated as the egg hatches, long grooves about $1 \mu \mathrm{m}$ thick are uniformly formed transversely. These long grooves facilitate the separation of the operculum through body expansion at the time of hatching.
\end{abstract}

Key Words: Head louse, Nit, Operculum, Pediculus humanus capitis, Scanning electron microscope

\section{INTRODUCTION}

Approximately 1.6\% 13\% of elementary school students in the world and $4.1 \%$ of Korea are infected with head lice (Pediculus humanus capitis) (Counahan et al., 2004; Ko \& Elston, 2004; Leung et al., 2005; Oh et al., 2010). Children become infected by other children though head contact (Takano-Lee et al., 2005) or sharing hats.

When completely mature lice mate, a female louse may spawn about 56 eggs at a time. A female louse lays $3 \sim 10$ eggs a day after mating and spawns $60 \sim 100$ eggs over $4 \sim 5$ weeks (Roberts, 2002; Arriaza et al., 2013). During spawning, a female louse secretes cement-like glue from a uterine gland at the abdomen tip called the gonopod in order to securely attach the eggs to hairs. A nit, the case of the eggs, is made up of protein that is similar to hair keratin (Burkhart \& Burkhart, 2005).
During spawning, eggs adhere to hairs through the nit, an egg case made of chitin. When eggs are laid, glue is discharged through movement of the abdomen tip of the head louse. A pair of projections at the abdomen tip called terminal lobes helps to locate a proper place for oviposition. Terminal lobes facilitate the secretion of glue at the collateral gland and also make the eggs attach to the hairs accurately (Burkhart \& Burkhart, 2007). A pair of gonopods is located at this abdomen terminal segment, which makes the solution spread well on the hydrophobic surface and helps to form the nit. The glue rapidly oxidizes and hardens when it is exposed to air after being secreted (Burkhart and Burkhart, 2005, 2007).

Eggs stick to the hairs near to the scalp, which helps maintain proper temperature and humidity for hatching (Mazurek \& Lee, 2000). The eggs are originally a milky color, but hatched nymphs are in white (Chosidow, 2000). A egg is oval-shaped, $0.8 \mathrm{~mm}$ in length, and the operculum is always on the side

This work was supported by Research Foundation from Hanseo University in 2011.

(a) This is an open-access article distributed under the terms of the Creative Commons Attribution Non-Commercial License (http://creativecommons.org/licenses/by-nc/3.0) which permits unrestricted noncommercial use, distribution, and reproduction in any medium, provided the original work is properly cited.

Copyrights (c) 2014 by Korean Society of Microscopy 
opposite to the scalp (Burkhart \& Burkhart, 2005).

Many studies have been reported about the disinfestation of head lice, as well as infection status surveys and the composition of the nit sheath (Hunter \& Barker, 2003; Elston, 2005; Clark, 2009; Lee et al., 2009; Oh et al., 2010; Gallardo et al., 2012). However, studies on the morphological characteristics of eggs have been insufficient. In the present study, the morphologic features of eggs inhabiting the scalp of Korean children were observed with scanning electron microscopy.

\section{MATERIALS AND METHODS}

\section{Materials for Experiment}

Eggs were collected from a male third grader from Korean elementary.

\section{Observation with Scanning Electron Microscopy}

The eggs were pre-fixed for an hour with $2.5 \%$ paraformaldehydeglutaraldehyde $\left(4^{\circ} \mathrm{C}\right.$, phosphate buffer, $\mathrm{pH}$ 7.4), cleaned twice for 15 minutes each with $0.4 \mathrm{M}$ phosphate buffer $\left(4^{\circ} \mathrm{C}, \mathrm{pH} 7.4\right)$, and then post-fixed for an hour with $1 \% \mathrm{OsO}_{4}\left(4^{\circ} \mathrm{C}\right.$, phosphate buffer).

After fixation, the material was washed with the same phosphate buffer $\left(4^{\circ} \mathrm{C}, \mathrm{pH} 7.4\right)$ twice for 15 minutes each and dehydrated with increasing concentrations of ethanol, which was then replaced with isoamyl acetate.

The processed material was dried in a critical point dryer (Hitachi SCP-II; Hitachi, Japan) and platinum coated by an ion coater (IB-5 ion coater; Eiko, Japan) with $20 \mathrm{~nm}$ thickness. Observations were then carried out (S-4700; Hitachi) at 15 $\mathrm{kV}$.

\section{RESULTS}

An egg attached to a hair shaft is morphologically divided into 4 parts: (1) the nit body, where eggs are contained until hatching, (2) aerophyles, which are respiratory pathways, (3) the operculum, and (4) the cementum, which fixes an egg to a hair shaft (Fig. 1).

The overall length of an egg was about $1.5 \mathrm{~mm}$ from the cementum to the aerophyle. The length of the cementum, which completely encloses the hair shaft, was $1 \mathrm{~mm}$, and the body was $800 \mu \mathrm{m}$ long (Fig. 1B). There are 10 protruding aerophyles in the flat operculum on the side of the hair shaft surface that are concentrated in a circular shape. The operculum in the egg that is attached to the hair shaft is located on the side opposite to the scalp (Fig. 1).

The thickness of the cementum in the area where the female louse starts surrounding the hair shaft by secreting chitin was about $4 \mu \mathrm{m}$ (Fig. 2A), and the thickness at the area from the body of a egg to the end of the attachment was about $20 \mu \mathrm{m}$ (Fig. 2B). It was observed that the thickness of the cementum at the end toward the nit body was 5 times thicker than at the end toward the scalp (Fig. 2B).

In addition, a comb-patterned structure formed in the area connecting the nit body and the end of the cementum (Fig. 2B).

The nit body formed from the place of $2 / 3$ of the cementum. The area extend from the cementum to the nit body and a smooth and fluent curved surface (Fig. 2C).

The diameter of the operculum in the apical area of the nit body is $270 \mu \mathrm{m}$ and circular in shape. On the surface of the operculum, there are 10 protruding aerophyls to the side of the hair shaft surface that are concentrated in a dome-like shape. Seven aerophyls closely surround 3 aerophyls at the center (Fig. 3A).
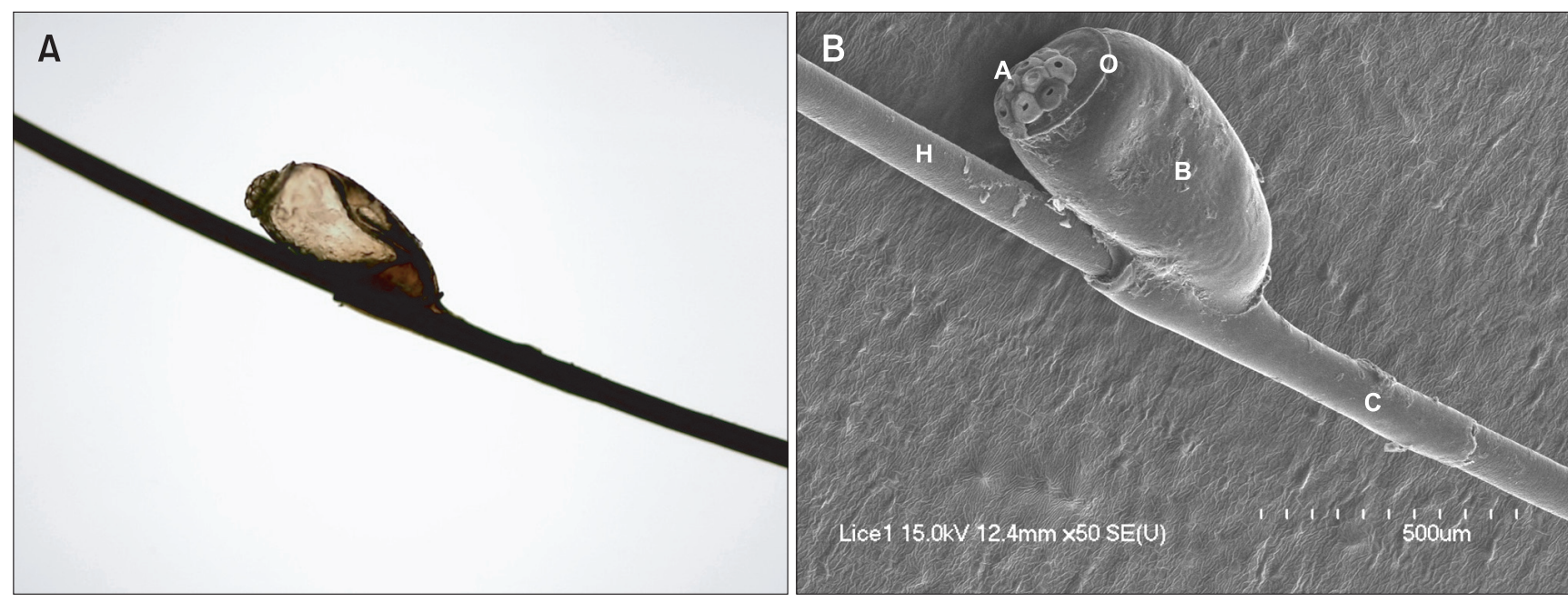

Fig. 1. Light (A) and scanning electron (B) micrographs of the egg of a head louse. H, hair shaft; A, aerophyles; O, operculum; B, nit body; C, cementum. 

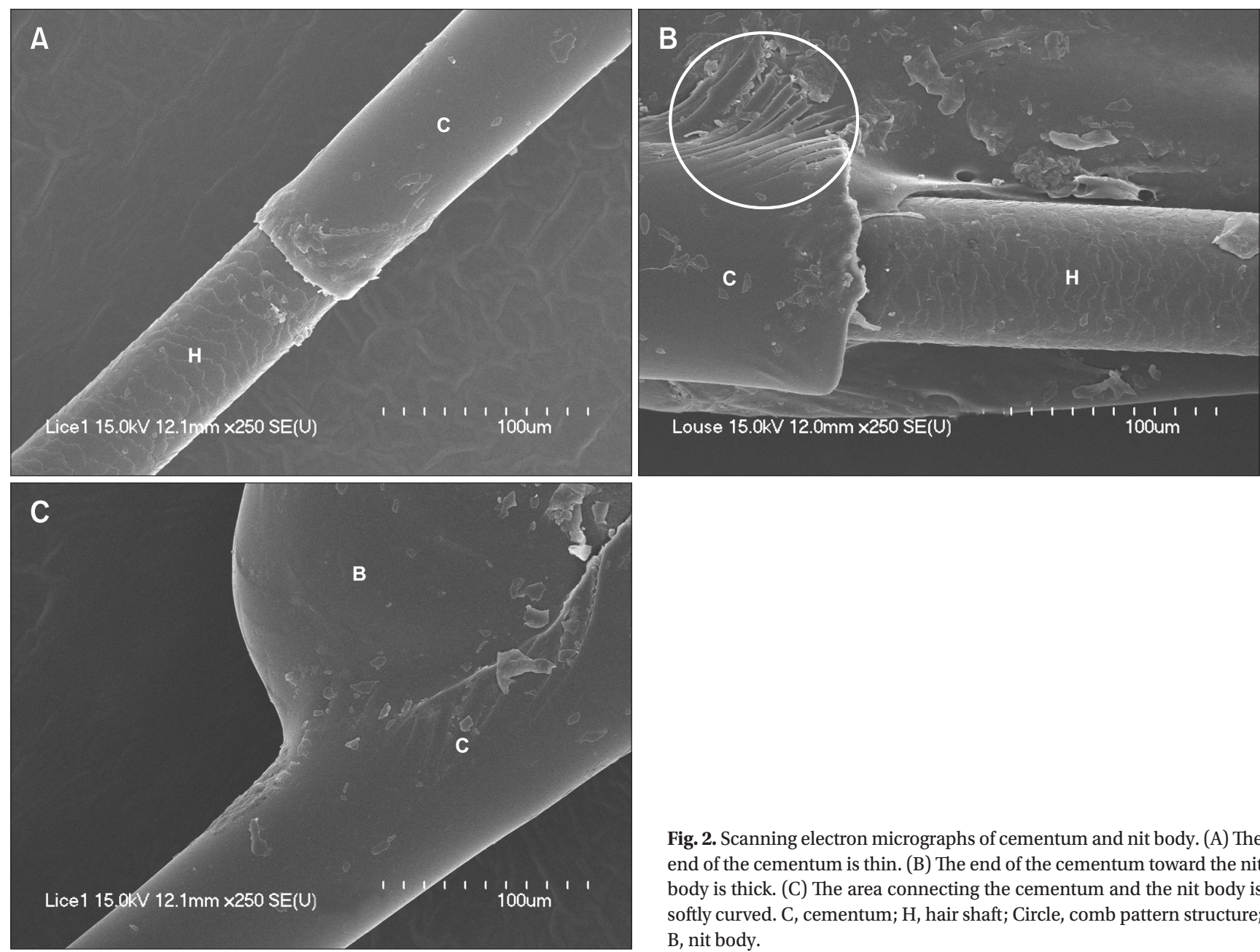

Fig. 2. Scanning electron micrographs of cementum and nit body. (A) The end of the cementum is thin. (B) The end of the cementum toward the nit body is thick. (C) The area connecting the cementum and the nit body is softly curved. C, cementum; $\mathrm{H}$, hair shaft; Circle, comb pattern structure; B, nit body.
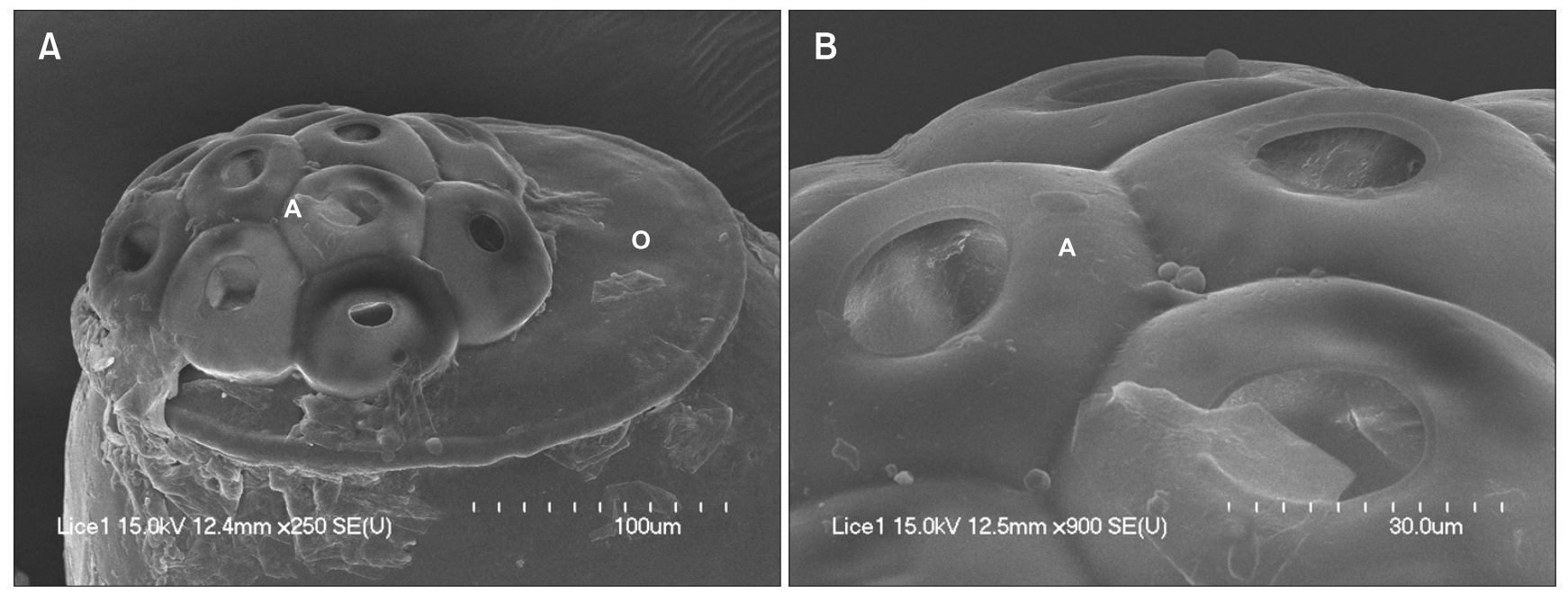

Fig. 3. Scanning electron micrographs of operculum. (A) Ten aerophyles exist to side of the hair shaft surface on the surface of the operculum. The picture shows that the 7 outer aerophyles closely surround 3 aerophyls at the center. (B) A magnified micrograph of Fig. 3A showing the dome-shaped aerophyles. A, aerophyles; $\mathrm{O}$, operculum. 

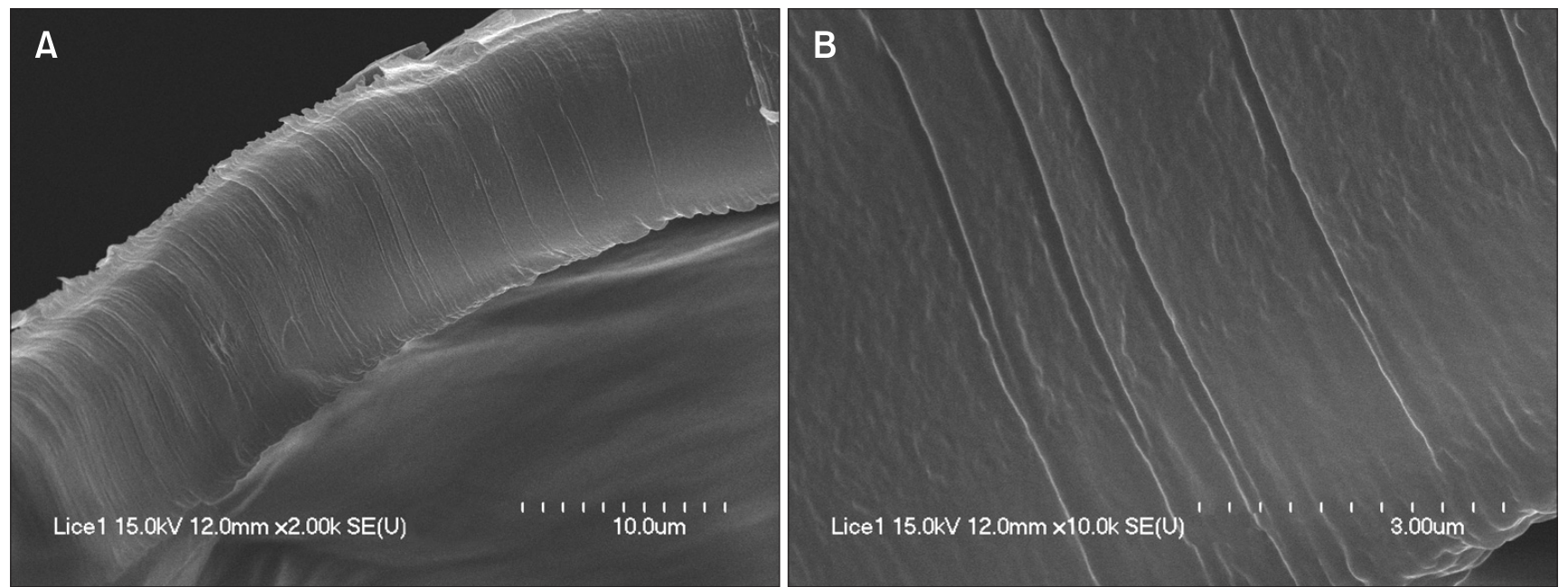

Fig. 4. Scanning electron micrographs of cut surface of a nit after egg hatching and separation of the operculum. (A) Uniform grooves are formed transversely on the whole cut surface. (B) High magnification scanning electron micrograph of Fig. 4A.
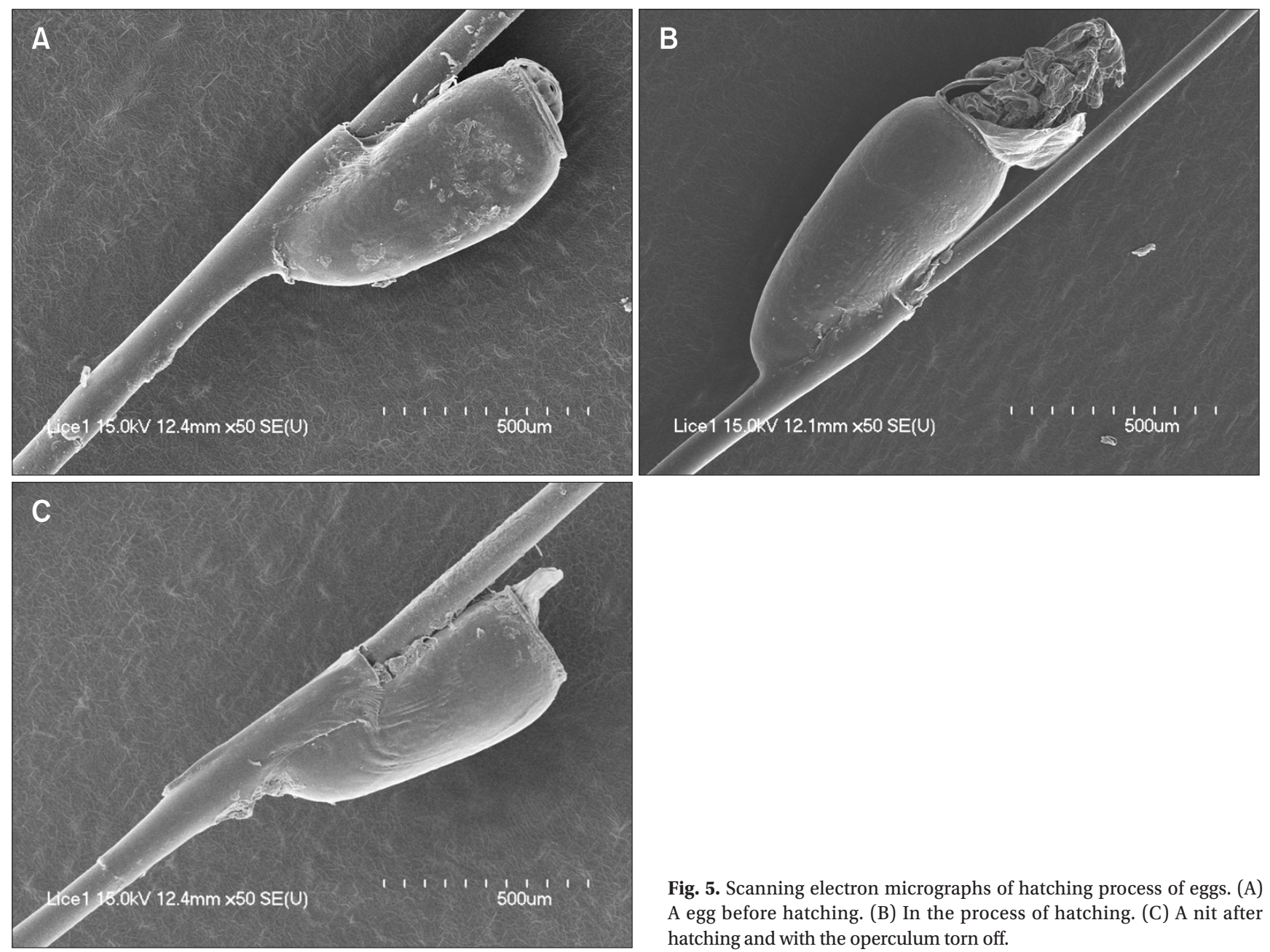

Fig. 5. Scanning electron micrographs of hatching process of eggs. (A) A egg before hatching. (B) In the process of hatching. (C) A nit after hatching and with the operculum torn off. 
Each aerophyl is shaped like a circular dome about $65 \mu \mathrm{m}$ in diameter with a hole, for the air pathway, at the center. The size of the hole in an aerophyl was 15 25 $\mu \mathrm{m}$ (Fig. 3B).

In the process of egg hatching, the operculum is torn, and separated from the body. Observation of the fine structure of the area of separation with a scanning electron microscope revealed that the thickness of the cut surface was about 11 $\mu \mathrm{m}$, and that long grooves were formed transversely on the cut surface at the time of separation (Fig. 4A).

The cut surface is smooth except for the long and slender grooves formed uniformly on it (Fig. 4B).

The process of eggs hatching starts with tearing the flat area with no aerophyls on the surface of the operculum (Fig. 5). Then, the head part of a nymph starts to come out (Fig. 5B). After the completion of hatching, only the nit body is left in the egg case with the operculum completely torn off (Fig. 5C).

\section{DISCUSSION}

A egg found in the scalp hairs of a Korean child was divided into 4 parts: nit body, aerophyles, the operculum, and the cementum, The length of a egg attached to a hair shaft was 1.5 $\mathrm{mm}$ from the end of the cementum to the aerophyle which was longer than the report of Burkhart \& Burkhart (2005). They reported it $800 \mu \mathrm{m}$, which was same to the length of the body in our study.

The cementum surrounding the hair shaft firmly, and the com-patterned structure connecting the nit body to the cementum makes the eggs not easily detached from the hair shaft. Also a nit is made of chitin protein, an insoluble polymer, and tyrosine and phenylalanine residues, which make the nit sheath harden (Burkhart \& Burkhart, 2005; Elston, 2005). The nit body in this experiment is connected from the $2 / 3$ of cementum and shaped like a goblet toward the apical direction of the hair shaft unlike the ovoid shape reported by Ibarra \& Hall (1996).

Mehlhorn et al. (2011) reported that there were 11 protruding aerophyles on the operculum of a head louse egg. In this study, however, the head louse egg had 10 aerophyles on the operculum.

In addition, the dome-shaped aerophyles exist to the side of the hair shaft from the surface of the operculum and cover only $2 / 3$ of the operculum. We suggest that these differences is may be inherent according to the seasons, climates and temperatures of the habitat.

When eggs are hatched and nymphs are come out of a egg case, the operculum is separated. We found that long grooves were uniformly created transversely on the cut surface at the time of separation. The long grooves on the cut surface may help the nymph to come out of the nit case easily.

\section{SUMMARY}

Nit, formed with glues secreted from female lice, surrounds hair shaft with a length of about $1.5 \mathrm{~mm}$. A nit body containing eggs is goblet in shape, and is $800 \mu \mathrm{m}$ long. The surface of nit sheath is very smooth, and the operculum at the apiculus area consists of 10 aerophyles. Operculums circular in shape with a diameter of $270 \mu \mathrm{m}$ have 7 aerophyles surrounding 3 central aerophyles. Each aerophyle is dome shape with diameter of $65 \mu \mathrm{m}$ having $15 \sim 25 \mu \mathrm{m}$ hole opened at the center. On the cut surface separated after eggs are hatched, about $1 \mu \mathrm{m}$ thick long grooves are uniformly formed from inside to outside of the nit case. These long grooves may play a role to make protein cap separated easily through body expansion at the time of hatching of eggs.

\section{CONFLICT OF INTEREST}

No potential conflict of interest relevant to this article was reported.

\section{ACKNOWLEDGMENTS}

The authors are grateful to the staff at the University for financial support.

\section{REFERENCES}

Arriaza B, Standen V, Nunez H, and Reinhard K (2013) Study of archaeological nits/eggs of Pediculus humanus capitis by scanning electron microscopy. Micron. 45, 145-149.

Burkhart C N and Burkhart C G (2005) Head lice: scientific assessment of the nit sheath with clinical ramifications and therapeutic options. $J$. Am. Acad. Dermatol. 53, 129-133.

Burkhart C N and Burkhart C G (2007) Fomite transmission in head lice. J. Am. Acad. Dermatol. 56, 1044-1047.

Chosidow O (2000) Scobies and pediculosis. Lancet 355, 819-826.

Clark J M (2009) Determination, mechanism and monitoring of knockdown resistance in permethrin resistant human head lice. Pediculus humanus capitis. J. Asia-Pacific Entomol. 12, 1-7.

Counahan M, Andrews R, Buttner P, Byrnes G, and Speare R (2004) Head lice prevalence in primary schools in Victoria, Australia. J. Pediatr. Child Health 40, 616-619.

Elston D K (2005) Nit picking. J. Am. Acad. Dermatol. 53, 164-167.

Gallardo A, Mougabure-Cueto G, Vassena C, Picollo M I, and Tolaza A C (2012) Comparative efficacy of new commercial pediculicides against adults and eggs of Pediculus humanus capitis (head lice). Parasitol. Res. 110, 1601-1606. 
Hunter J A and Barker S C (2003) Susceptibility of head lice (Pediculus humanus capitis) to pediculicides in Australia. Parasitol. Res. 90, 476-478.

Ibarra J and Hall D M B (1996) Head lice in schoolchildren. Arch. Dis. Child 75, 471-473.

Ko C J and Elston D M (2004) Pediculosis. J. Am. Acad. Dermatol. 50, 1-12.

Lee S H, Clark J M, Ahn Y J, Lee W J, Yoon K S, Kwon D H, and Seong K M (2009) Molecular mechanisms and monitoring of permethrin resistance in human head lice. Pestic. Biochem. Physiol. 97, 109114.

Leung A K C, Fong J H S, and Pinto-Rojas A (2005) Pediculosis capitis. J. Pediatr. Health Care 19, 369-373.
Mazurek C M and Lee N P (2000) How to manage head lice. West J. Med. 172, 342-345.

Mehlhorn H, Abdel-Ghaffar F, Al-Rasheid K A S, Schmidt J, and Semmler $M$ (2011) Ovicidal effects of a need seed extract preparation on eggs of body and head lice. Parasitol. Res. 109, 1299-1302.

Oh J M, Lee I Y, Lee W J, Seo M, Park S A, Lee S H, Seo J H, Yong T S, Park S J, Shin M H, Pai K S, Yu J R, and Sim S B (2010) Prevalence of pediculosis capitis among Korean children. Parasitol. Res. 107, 1415-1419.

Roberts R J (2002) Head lice. New Engl. J. Med. 346, 1645-1650.

Takano-Lee M, Edman D, Mullens B A, and Clark J M (2005) Transmission potential of the human head louse, Pediculus capitis (Anoplura: Pediculidae). Int. J. Dermatol. 44, 811-816. 